\title{
Screening for brain metastases in patients with stage III non-small cell lung cancer: Is there additive value of magnetic resonance imaging above a contrast- enhanced computed tomography of the brain?
}

Citation for published version (APA):

Hendriks, L. E. L. ., Bootsma, G. P., de Ruysscher, D. K. M., Scheppers, N. A. M., Hofmane, P. A. M., Brans, B. T., \& Dingemans, A-M. C. (2013). Screening for brain metastases in patients with stage III nonsmall cell lung cancer: Is there additive value of magnetic resonance imaging above a contrast-enhanced computed tomography of the brain? Lung Cancer, 80(3), 293-297.

https://doi.org/10.1016/j.lungcan.2013.02.006

Document status and date:

Published: 01/06/2013

DOI:

10.1016/j.lungcan.2013.02.006

Document Version:

Publisher's PDF, also known as Version of record

Document license:

Taverne

Please check the document version of this publication:

- A submitted manuscript is the version of the article upon submission and before peer-review. There can be important differences between the submitted version and the official published version of record. People interested in the research are advised to contact the author for the final version of the publication, or visit the DOI to the publisher's website.

- The final author version and the galley proof are versions of the publication after peer review.

- The final published version features the final layout of the paper including the volume, issue and page numbers.

Link to publication

\footnotetext{
General rights rights.

- You may freely distribute the URL identifying the publication in the public portal. please follow below link for the End User Agreement:

www.umlib.nl/taverne-license

Take down policy

If you believe that this document breaches copyright please contact us at:

repository@maastrichtuniversity.nl

providing details and we will investigate your claim.
}

Copyright and moral rights for the publications made accessible in the public portal are retained by the authors and/or other copyright owners and it is a condition of accessing publications that users recognise and abide by the legal requirements associated with these

- Users may download and print one copy of any publication from the public portal for the purpose of private study or research.

- You may not further distribute the material or use it for any profit-making activity or commercial gain

If the publication is distributed under the terms of Article 25fa of the Dutch Copyright Act, indicated by the "Taverne" license above,

Download date: 26 Apr. 2023 


\title{
Screening for brain metastases in patients with stage III non-small cell lung cancer: Is there additive value of magnetic resonance imaging above a contrast-enhanced computed tomography of the brain?
}

\author{
Lizza E.L. Hendriks ${ }^{\mathrm{a}, \mathrm{b}, *}$, Gerben P. Bootsma ${ }^{\mathrm{a}}$, Dirk K.M. de Ruysscher ${ }^{\mathrm{c}, \mathrm{d}}$, Nicole A.M. Scheppers ${ }^{\mathrm{a}}$, \\ Paul A.M. Hofman ${ }^{\mathrm{e}}$, Boudewijn T. Brans ${ }^{\mathrm{f}}$, Anne-Marie C. Dingemans ${ }^{\mathrm{b}}$ \\ a Department of Pulmonology, Atrium Medical Centre, H. Dunantstraat 5, 6401 CX, Heerlen, The Netherlands \\ ${ }^{\mathrm{b}}$ Department of Pulmonology, Maastricht University Medical Centre+, P.O. Box 5800, 6202 AZ, Maastricht, The Netherlands

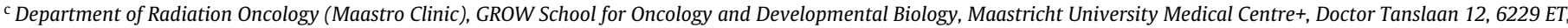 \\ Maastricht, The Netherlands \\ ${ }^{\mathrm{d}}$ Department of Radiation Oncology, Leuven Cancer Institute, University Hospitals Leuven/KU Leuven, Herestraat 49, 3000 Leuven, Belgium \\ e Department of Radiology, Maastricht University Medical Centre+, P.O. Box 5800, 6202 AZ, Maastricht, The Netherlands \\ ${ }^{\mathrm{f}}$ Department of Nuclear Medicine, Maastricht University Medical Centre+, P.O. Box 5800, 6202 AZ, Maastricht, The Netherlands
}

\section{A R T I C L E I N F O}

\section{Article history:}

Received 28 November 2012

Received in revised form 22 January 2013

Accepted 5 February 2013

\section{Keywords:}

Non small cell lung cancer

Magnetic resonance imaging

Computed tomography

Staging

${ }^{18}$ FDG-PET

Brain metastases

\begin{abstract}
A B S T R A C T
Introduction: Stage III NSCLC patients are candidates for treatment with curative intent. Current guidelines advise post contrast magnetic resonance imaging (MRI) or contrast enhanced computed tomography (CE-CT) of the brain in these patients to exclude brain metastases (BM). In previous small studies MRI was reported to be superior to CE-CT. However, CT and MR technology have evolved and ${ }^{18} \mathrm{~F}-$ deoxyglucose-positron-emission-tomography $\left({ }^{18}\right.$ FDG-PET) has been implemented in staging of NSCLC. If CE-CT, performed together with ${ }^{18}$ FDG-PET-CT shows the same yield of BM detection as an additionally performed MRI, substantial gain in time and resources is expected.

Methods: All NSCLC patients who underwent a staging ${ }^{18}$ FDG-PET-CT between January 2008 and September 2011 were reviewed. Neurological asymptomatic patients with stage III NSCLC who were eligible for treatment with curative intent were selected, without taking into account the results of brain MRI. CT was compared to MRI to investigate whether additional BM were detected on MRI. Development of BM within a year after negative MRI was recorded.

Results: 97/429 NSCLC patients who underwent a PET-CT had stage III disease. Three otherwise stage III patients already had occult BM on CE-CT. 77/97 (79\%) patients underwent MRI, 45/77 (58\%) CE-CT and 32/77 (42\%) LD-CT. In none of the CE-CT, but in 5/32 (16\%) LD-CT patients BM were detected on MRI. 9/72 patients (13\%) without BM on MRI at diagnosis developed BM within a year.

Conclusions: This retrospective study suggests that there is no additive value of MRI to ${ }^{18} \mathrm{FDG}$-PET-CT with CE-CT in screening for BM in neurological asymptomatic patients with stage III NSCLC.
\end{abstract}

(c) 2013 Elsevier Ireland Ltd. All rights reserved.

\section{Introduction}

Around $30 \%$ of patients with non small cell lung cancer (NSCLC) present with stage III disease and are candidates for intense combined modality treatment with curative intent [1]. The outcome is however still poor, with 5 year survival rate of $15.1 \%$ [1].

As the brain is a common site for dissemination [2], national and international guidelines advise to exclude brain metastases before starting intense treatment in this patient population. The combined modality treatment with concurrent chemoradiotherapy is

\footnotetext{
* Corresponding author at: Maastricht University Medical Centre+, P.O. Box 5800, 6202 AZ Maastricht, The Netherlands. Tel.: +31 033871318; fax: +31 033875051

E-mail address: lizza.hendriks@mumc.nl (L.E.L. Hendriks).
}

frequently associated with morbidity due to radiation esophagitis and pneumonitis [3-5]. It is estimated that, dependent on disease stage and choice of radiological evaluation, 10-24\% of NSCLC patients at presentation have one or more asymptomatic brain metastases $[2,6,7]$. For example, up to $16 \%$ otherwise stage III NSCLC patients were diagnosed with brain metastases on post contrast magnetic resonance imaging (MRI). However, in this study published in 2003, the number of patients with stage III NSCLC was small (38 of 91 patients) and ${ }^{18} \mathrm{~F}$-deoxyglucose-positron emission tomography ( ${ }^{18} \mathrm{FDG}$-PET) scanning was not performed to exclude extracranial metastases [2].

A whole body ${ }^{18}$ FDG-PET is in current guidelines advised in the diagnostic work up of all patients eligible for therapy with curative intent to exclude extracranial metastases [3-5] ${ }^{18} \mathrm{FDG}$ PET-scanning alone is not effective in detecting (asymptomatic) 
brain metastases [8,9] Nowadays, combined PET-CT scanners are more frequently used. In these scanners a ${ }^{18}$ FDG-PET can be performed with a non-diagnostic low dose computed tomography (LD-CT) for attenuation correction or with a diagnostic contrast enhanced CT (CE-CT) of the thorax and upper abdomen. Combination with CE-CT of the brain is also an option and feasible, but is not common practice [10]. ${ }^{18}$ FDG-PET-scanning with LD-CT for attenuation correction has already been proven not to be effective in detecting asymptomatic brain metastases when compared to MRI [11].

Post contrast MRI is reported to be superior to CE-CT in diagnosing occult brain metastases. However, these were mostly older studies, all including patients with mixed tumour types and tumour stages [7,12-14].

In addition, CT and MR technology both have evolved significantly. Moreover, in none of the studies mentioned above a ${ }^{18}$ FDG-PET(-CT) was part of the diagnostic work up, leading to a less well staged patient population [15].

Lung cancer guidelines advice routine screening for brain metastases with post contrast MRI or CE-CT in all patients with stage III NSCLC eligible for therapy with curative intent $[3-5,15,16]$. In 3 guidelines, NCCN, ESMO and the Dutch VIKC, a post contrast MRI is advised [4,5,16]. However, in most hospitals MRI is difficult to arrange within a reasonable time scale. There are also contraindications for MRI as intracorporal metallic objects, pacemakers and claustrophobia.

The question whether post contrast MRI offers a benefit to CE$\mathrm{CT}$ in the initial staging of patients with NSCLC has become more urgent in view of the increasing wide-spread use of ${ }^{18}$ FDG-PET-CT scanners. If dedicated CE-CT of the brain performed in the same setting as ${ }^{18}$ FDG-PET-CT could lead to the same yield of detection of brain metastases as ${ }^{18}$ FDG-PET-CT with a non-diagnostic LD-CT for attenuation correction and a separate post contrast MRI, a substantial gain in time and resources can be expected. In this retrospective study we evaluated whether there is additive value of post contrast MRI to CE-CT for the detection of asymptomatic brain metastases when both are performed in standard work-up including ${ }^{18}$ FDG-PET-CT.

\section{Materials and methods}

\subsection{Patient selection}

The ${ }^{18}$ FDG-PET-CT database of the university hospital Maastricht, The Netherlands, was reviewed. All patients who underwent ${ }^{18}$ FDG-PET-CT in the diagnostic work-up for lung cancer between January 2008 and September 2011 were further evaluated. Patients with stage III NSCLC disease after staging with the ${ }^{18}$ FDG-PETCT and who were candidates for treatment with curative intent were selected. Patients with neurological symptoms requiring brain imaging were excluded. In our hospital standard work-up of patients admitted with suspicion of lung cancer includes a ${ }^{18}$ FDGPET according to a specific lung cancer protocol which consists of a CE-CT of the brain, thorax and upper-abdomen combined with the ${ }^{18}$ FDG-PET. In case a CE-CT of the chest and upper abdomen is already performed separately the ${ }^{18}$ FDG-PET is combined with a non-diagnostic LD-CT for attenuation correction. As a consequence, in these cases only a non-diagnostic LD-CT of the brain was available. Both patients who underwent a LD-CT together with the PET-CT and patients who underwent a CE-CT were analyzed. The policy in our institute is to screen for brain metastases in otherwise stage III NSCLC patients by MRI, also when a CE-CT of the brain is already performed. The results of the MRI were studied to investigate whether additional asymptomatic brain metastases were detected on MRI. In addition development of symptomatic brain metastases within a year after a negative scan was scored.

This study has been approved by the medical ethical committee of the university hospital Maastricht.

\subsection{Imaging protocols}

\subsubsection{MRI protocol}

MRI was performed with a $1.5 \mathrm{~T}$ MRI system using a 8-channel Sens head coil (Philips Healthcare, Best, The Netherlands). The protocol included a T1 weighted spin-echo sequence with a magnetization prepulse ((MTC) (TR 615, TE 14, NEX 2, matrix 2568154, with an on resonance prepulse), with and without $0.1 \mathrm{mmol} / \mathrm{kg}$ body weight of Gadobutrol. The addition of the MTC prepulse results in an increased enhancement equivalent to a double doses of gadolinium contrast. Additionally a T2 weighted turbo-spin echo sequence (TR 4632, TE 100 , ETL 12 , NEX 2, matrix $256 \times 192$ ) and a fluid attenuated inversion recovery sequence (TR 8000, TE 120 , TI 2000, ETL 23, NEX 1, matrix $512 \times 138$ ). All sequence had a slice thickness of $5 \mathrm{~mm}$ with a gap of $0.5 \mathrm{~mm}$. Additionally a T1 weighted gradient echo sequence was performed with isotropic voxels of $1 \mathrm{~mm}$ (TR 9, TE 4, NEX 1, matrix $256 \times 256$ ).

\subsubsection{PET-CT protocol}

Acquisition of ${ }^{18}$ FDG-PET-CT was performed using a PET camera equipped with time-of-flight (Gemini TF PET/64-slice CT scanner, Philips, Best, The Netherlands). PET scans were made from head to pelvis, using 10 bed positions of $2.5 \mathrm{~min}$ each, after injection of ${ }^{18} \mathrm{FDG}$. In selected cases imaging was continued. Reconstruction was performed using a standard protocol in 3D with a matrix size of 144 resulting in a voxel size of $4.0 \mathrm{~mm} \times 4.0 \mathrm{~mm} \times 4.0 \mathrm{~mm}$. PET was preceded by a LD-CT ( $120 \mathrm{keV}, 30 \mathrm{mAs}, 4 \mathrm{~mm}$ slice thickness, 4,0 increment) for attenuation correction of the PET images. Supplementary high-dose, CE-CT was performed according to a protocol with a standardized sequence following injection of $150 \mathrm{ml}$ and a flow rate of $3 \mathrm{ml} / \mathrm{s}$ of jopromide (Ultravist, Bayer, Berlin, Germany): The diagnostic brain CT $(120 \mathrm{kV}, 400 \mathrm{mAs})$ was performed with a slice thickness of $0.8 \mathrm{~mm}$ and reconstructed to $5 \mathrm{~mm}$ thick slices. The scan was performed 3 minutes after administration of the jopromide.

\section{Results}

$4131{ }^{18}$ FDG-PET-CT scans were reviewed. From the $510{ }^{18}$ FDGPET-CT's performed in the diagnostic work-up for lung cancer, 429 patients were diagnosed with NSCLC. 3 patients with otherwise stage III disease had occult brain metastases on CE-CT. 112 of 429 patients were diagnosed with stage III disease after PET-CT. 97 of $112(87 \%)$ stage III patients were eligible for therapy with curative treatment. 77 of 97 (79\%) patients underwent MRI (Fig. 1). Patient characteristics of these 77 patients are shown in Table 1. Although the standard work-up consisted of a MRI, the MRI was not performed in 20 patients because of diagnostic work-up elsewhere $(n=3)$, contra-indication for MRI $(n=2)$, participation in a study in which MRI of the brain was not a requisite $(n=5)$, deterioration of clinical condition before MRI was made $(n=2)$ or patient decision not to undergo therapy with curative intent $(n=2)$. In 6 patients no reason was found for not performing MRI.

In 45 of 77 (58\%) patients a CE-CT was performed and in 32 of 77 (42\%) patients only a LD-CT was done together with the ${ }^{18}$ FDG-PET. In the LD-CT patient group a CE-CT of the thorax and upper abdomen was already available before the ${ }^{18}$ FDG-PET-CT was made. In these cases only a LD-CT was performed combined with the ${ }^{18}$ FDG-PET for attenuation. As a consequence, no diagnostic scan of the brain was available in these patients. 


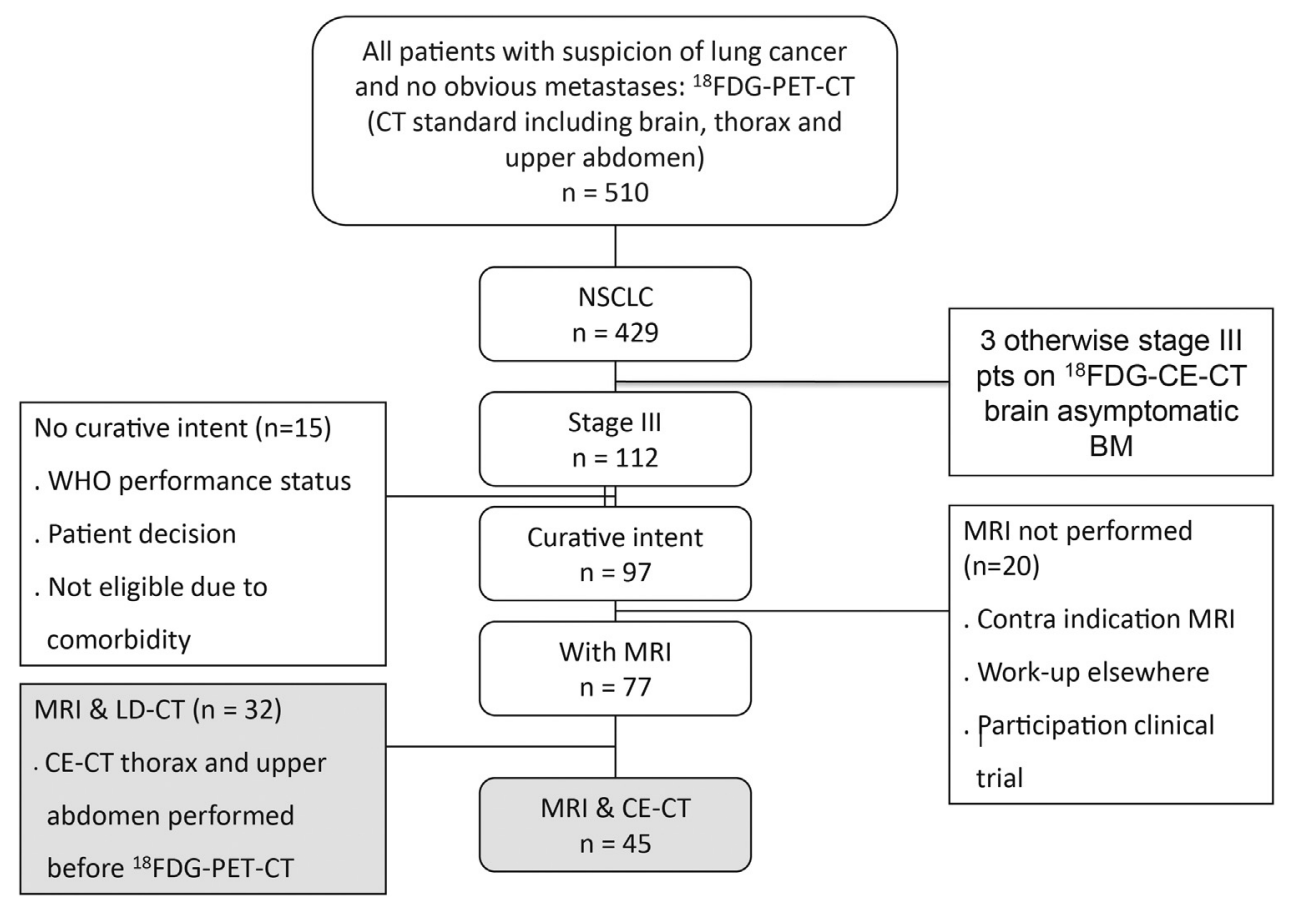

Fig. 1. Flowchart work-up stage III NSCLC.

Table 1

patient characteristics stage III NSCLC patients in whom MRI was made.

\begin{tabular}{|c|c|}
\hline Sex (male/female) & $46 / 31$ \\
\hline Age (years) range & 64.9 range 10.2 \\
\hline \multicolumn{2}{|l|}{ WHO performance score $(0-4)$} \\
\hline (c) & 41 \\
\hline 1 & 30 \\
\hline 2 & 4 \\
\hline 3 & 2 \\
\hline 4 & 0 \\
\hline \multicolumn{2}{|l|}{ Stage (CE-CT/LD-CT) } \\
\hline IIIA & $37(19 / 18)$ \\
\hline cT1N2 & $2(0 / 2)$ \\
\hline cT2N2 & $13(6 / 7)$ \\
\hline cT3N1 & $1(0 / 1)$ \\
\hline cT3N2 & $8(6 / 2)$ \\
\hline cT4NO & $12(6 / 6)$ \\
\hline cT4N1 & $1(1 / 0)$ \\
\hline IIIB & $40(26 / 14)$ \\
\hline cT1N3 & $5(3 / 2)$ \\
\hline cT2N3 & $5(4 / 1)$ \\
\hline cT3N3 & $4(4 / 0)$ \\
\hline cT4N2 & $19(11 / 8)$ \\
\hline cT4N3 & $7(4 / 3)$ \\
\hline \multicolumn{2}{|l|}{ Pathology } \\
\hline Adeno carcinoma & 30 \\
\hline Squamous cell carcinoma & 24 \\
\hline Large cell carcinoma & 3 \\
\hline NSCLC-NOS & 20 \\
\hline \multicolumn{2}{|l|}{ Treatment } \\
\hline \multicolumn{2}{|l|}{ Curative intent } \\
\hline Chemoradiotherapy & 67 \\
\hline Surgery followed by chemo- and/or radiotherapy & 3 \\
\hline \multicolumn{2}{|l|}{$\begin{array}{l}\text { Palliative/BSC } \\
\text { a }\end{array}$} \\
\hline Chemotherapy & 3 \\
\hline Radiotherapy & 3 \\
\hline No treatment & 1 \\
\hline
\end{tabular}

Abbreviations: WHO: World Health Organization; NOS: not otherwise specified.

a The clinical condition of these patients deteriorated quickly during analysis, so only palliative treatment was offered.
In the negative $\mathrm{CE}-\mathrm{CT}$ group, 19 of 45 patients (42\%) had stage IIIA disease and 26 (58\%) had stage IIIB. In the LD-CT group, 18 of 32 patients (56\%) had stage IIIA disease and 14 (44\%) had stage IIIB ( $\mathrm{T}$ and $\mathrm{N}$ see Table 1 ).

In none of the 45 patients who had a negative CE-CT of the brain together with the ${ }^{18}$ FDG-PET scan, brain metastases were detected on MRI. In contrast, in 5 of 32 (16\%) LD-CT patients brain metastases were detected on MRI (Fig. 2). The MRI showed 2 metastases in 1 patient (largest $16(\mathrm{~mm})), 3$ metastases in 1 patient (all around $6 \mathrm{~mm}$ ) and multiple metastases in the other 3 patients (largest $12 \mathrm{~mm}$ ). Before MRI, these patients were staged as cT1N3, cT2N2, cT4N0, cT4N2 and cT4N3.

Within 1 year of the diagnosis 9 of $72(13 \%)$ patients without brain metastases on MRI at diagnosis developed symptomatic brain metastases, in 2 of 9 (22\%) also progressive disease outside of the brain was shown (Figs. 3 and 4). Of these 9 patients, 2 were initially diagnosed with a squamous cell carcinoma (initially cT2N3M0 and cT4NOMO), 4 with an adeno carcinoma (initially cT4N2M0, cT2N2M0, cT4N2M0, cT4NOM0) and in the remaining 3 patients the NSCLC was not otherwise specified (initially cT2N2M0, cT2N2M0, CT3N2M0). Of these 9 patients, 3 had a CE-CT followed by MRI during their initial work-up for lung cancer, 6 had a LD-CT followed by MRI during the initial work-up. To evaluate whether these brain metastases were missed during the initial work-up the imaging data of these 9 MRI's were reviewed by an experienced neuroradiologist $(\mathrm{PH})$, but also in retrospect no brain metastases were found.

\section{Discussion}

Brain metastases are frequent in stage III NSCLC [2]. Historically MRI is supposed to be superior to CT in detecting brain metastases $[2,7,12,14]$. However, the question is whether MRI has a clinical relevant benefit above CE-CT in detecting asymptomatic brain metastases in stage III NSCLC when using up-to-date staging techniques. In this study, up-to-date MRI and CT techniques were used and extra-cranial metastases were excluded by 


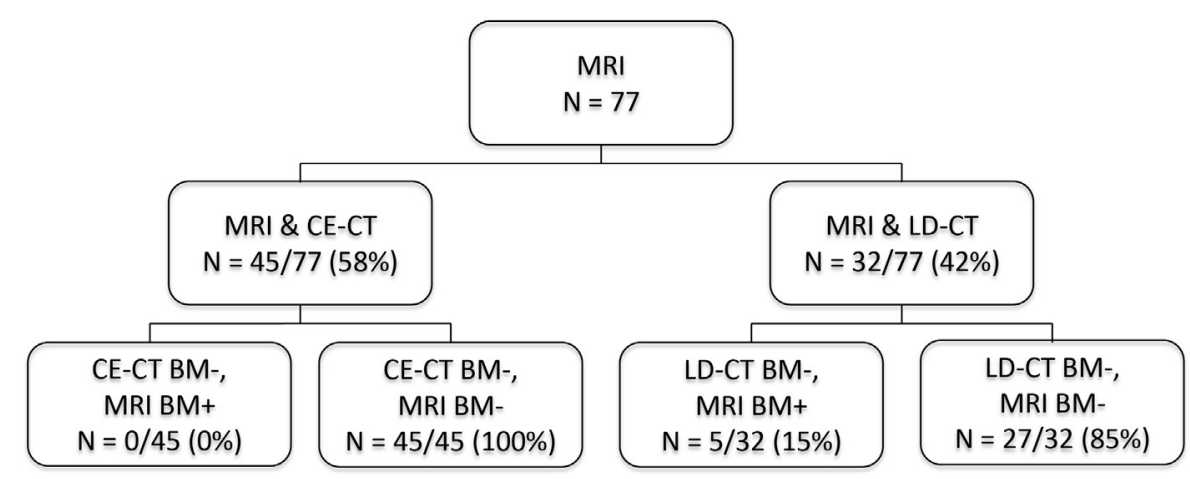

Fig. 2. Additional brain metastases found on MRI.

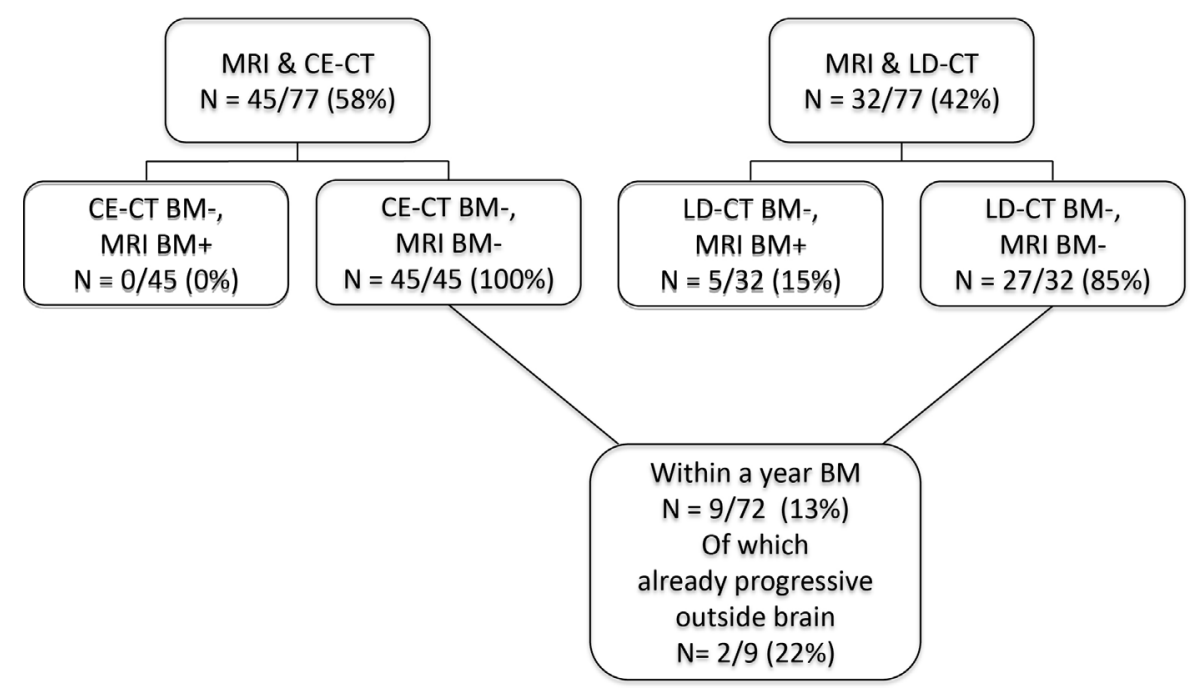

Fig. 3. Brain metastases within a year after initial negative MRI.

${ }^{18}$ FDG-PET-CT scanning. In this patient population MRI did not show additional brain metastases after a negative CE-CT of the brain combined with the ${ }^{18}$ FDG-PET-CT, but in three of 48 patients brain metastases were already found on the CE-CT.

Time to develop symptomatic BM

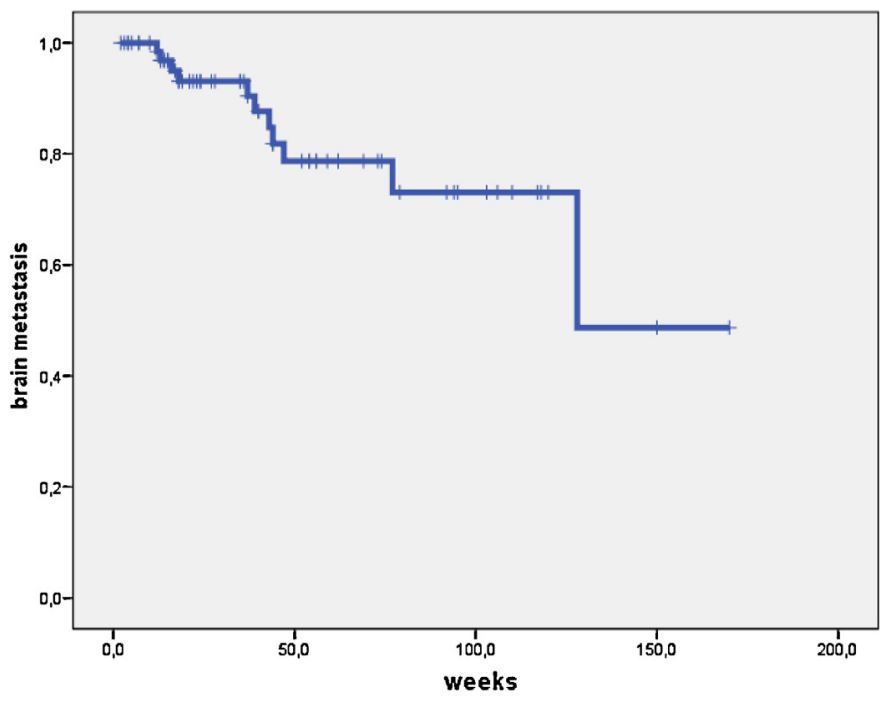

Fig. 4. Kaplan Meier curve, time to develop symptomatic brain metastasis.
Also, this study confirms that adequate imaging of the brain is mandated in these patients as in $16 \%$ of the patients who underwent solely a non diagnostic LD-CT of the brain, brain metastases were detected on MRI. This percentage is comparable to percentages of occult brain metastases found in other studies [2].

Substantial gain in time and resources can be expected when the whole diagnostic imaging work-up can be performed in one single procedure, this diagnostic work-up consisting of a ${ }^{18} \mathrm{FDG}$ PET directly followed by CE-CT of the brain, thorax and (upper) abdomen. Following this procedure there would also be no delay because of waiting time for MRI before starting therapy with curative intent. Furthermore, in most institutes access to $\mathrm{CT}$ is easier than to MRI.

Brain metastases are still a serious problem in patients with stage III NSCLC, in our series $13 \%$ of patients with an initially negative MRI developed brain metastases within a year. Probably it is worth to investigate whether these brain metastases can be detected at diagnosis when more sensitive MRI techniques are used. It is known that the sensitivity of a post contrast MRI can be increased by using higher dose of contrast or by 3.0 T MRI instead of $1.5 \mathrm{~T}$. However, higher contrast doses also increases false positive findings $[9,17,18]$. Moreover, although 3.0 T MRI scanners seem more sensitive in detecting cerebral lesions, no studies exist that show the increased sensitivity of 3.0 T systems for the detection of cerebral metastases. In our study we used MTC prepulse, this prepulse results in an increased enhancement equivalent to a double dose of gadolinium contrast [19]. The addition of post-contrast fluid attenuated inversion recovery (FLAIR) sequence (which we 
used) also improves diagnostic confidence in the evaluation of brain metastases [20]. Another option is to routinely follow stage III NSCLC patients treated for cure with MRI or CE-CT of the brain on a regular basis to detect brain metastases at a stage where radical treatment is possible. Trying to prevent the development of brain metastases is also an option. A recent phase III study showed that prophylactic cranial irradiation in NSCLC stage III without progressive disease after therapy decreased the rate of brain metastases but no effect on overall survival or disease free survival was found [21]. Another phase III randomized study addressing the same question is still open for patient enrolment (NVALT11/DLCRG 02).

There are some drawbacks of the current study. First, it is a retrospective study with a small sample size. However all consecutive patients were included in the analysis, decreasing the risk of bias. Second, not all stage III underwent a MRI. This was especially in 2008 when guidelines did not already advise post contrast MRI of the brain to exclude brain metastases. Third, not all patients were screened by CE-CT before MRI. In the LD-CT group a CE-CT of the thorax and upper abdomen was already available before the ${ }^{18}$ FDG-PET-CT was made (most times because the CT of the chest was made for other purpose than suspicion of cancer). In these cases the ${ }^{18}$ FDG-PET was only combined with a non-diagnostic LD-CT for attenuation. As a consequence no diagnostic scan of the brain was available. There were no differences in patient characteristics between the patients with LD-CT and CE-CT.

\section{Conclusion}

This retrospective study of a consecutive cohort of patients suggests that there is no additive value of post contrast MRI when ${ }^{18}$ FDG-PET-CT with CE-CT is performed in the diagnostic work-up of neurologically asymptomatic stage III NSCLC patients in screening for brain metastases. However, brain metastases is still an important problem as $13 \%$ of patients developed symptomatic brain metastases within 1 year after treatment with curative intent. Due to the possible impact of these findings on clinical practice a prospective trial (NTR3628) using up-to-date imaging techniques to validate these data has started.

\section{Conflicts of interest statement}

All authors declare no conflicts of interest.

\section{Funding source}

None declared.

\section{References}

[1] Auperin A, Le Pechoux C, Rolland E, et al. Meta-analysis of concomitant versus sequential radiochemotherapy in locally advanced non-small-cell lung cancer. J Clin Oncol 2010;28:2181-90.

[2] Hochstenbag MM, Twijnstra A, Hofman P, et al. MR-imaging of the brain of neurologic asymptomatic patients with large cell or adenocarcinoma of the lung. Does it influence prognosis and treatment? Lung Cancer 2003;42: 189-93.

[3] NICE clinical guideline 121. 2011 Lung cancer, the diagnosis and treatment of lung cancer; 2011.

[4] VIKC richtlijn niet-kleincellig longcarcinoom. Landelijke richtlijn, versie 2.0.; 2012.

[5] NCCN guidelines Non-Small Cell Lung Cancer version 3.2012; 2012.

[6] Kim SY, Kim JS, Park HS, et al. Screening of brain metastasis with limited magnetic resonance imaging (MRI): clinical implications of using limited brain MRI during initial staging for non-small cell lung cancer patients. J Korean Med Sci 2005;20:121-6.

[7] Suzuki K, Yamamoto M, Hasegawa Y, et al. Magnetic resonance imaging and computed tomography in the diagnoses of brain metastases of lung cancer. Lung Cancer 2004;46:357-60.

[8] Marom EM, McAdams HP, Erasmus JJ, et al. Staging non-small cell lung cancer with whole-body PET. Radiology 1999;212:803-9.

[9] Palm I, Hellwig D, Leutz M, et al. Brain metastases of lung cancer: diagnostic accuracy of positron emission tomography with fluorodeoxyglucose (FDGPET). Med Klin (Munich) 1999;94:224-7.

[10] Boellaard R, Oyen WJ, Hoekstra CJ, et al. The Netherlands protocol for standardisation and quantification of FDG whole body PET studies in multi-centre trials. Eur J Nucl Med Mol Imag 2008;35:2320-33.

[11] Yi CA, Shin KM, Lee KS, et al. Non-small cell lung cancer staging: efficacy comparison of integrated PET/CT versus 3.0-T whole-body MR imaging. Radiology 2008;248:632-42.

[12] Schellinger PD, Meinck HM, Thron A. Diagnostic accuracy of MRI compared to CCT in patients with brain metastases. J Neurooncol 1999;44:275-81.

[13] Seute T, Leffers P, ten Velde GP, et al. Detection of brain metastases from small cell lung cancer: consequences of changing imaging techniques (CT versus MRI). Cancer 2008;112:1827-34.

[14] Yokoi K, Kamiya N, Matsuguma H, et al. Detection of brain metastasis in potentially operable non-small cell lung cancer: a comparison of CT and MRI. Chest 1999;115:714-9.

[15] Silvestri GA, Gould MK, Margolis ML, et al. Noninvasive staging of non-small cell lung cancer: ACCP evidenced-based clinical practice guidelines (2nd edition). Chest 2007;132:178S-201S.

[16] Peters S, Adjei AA, Gridelli C, et al. Metastatic non-small-cell lung cancer (NSCLC): ESMO Clinical Practice Guidelines for diagnosis, treatment and followup. Ann Oncol 2012;23(Suppl. 7):vii56-64.

[17] Sze G, Johnson C, Kawamura Y, et al. Comparison of single- and triple-dose contrast material in the MR screening of brain metastases. Am J Neuroradiol 1998;19:821-8.

[18] Yuh WT, Tali ET, Nguyen HD, et al. The effect of contrast dose, imaging time, and lesion size in the MR detection of intracerebral metastasis. Am J Neuroradiol 1995; $16: 373-80$

[19] Finelli DA, Hurst GC, Gullapali RP, et al. Improved contrast of enhancing brain lesions on postgadolinium, T1-weighted spin-echo images with use of magnetization transfer. Radiology 1994;190:553-9.

[20] Terae S, Yoshida D, Kudo K, et al. imaging in combination with pre- and postcontrast magnetization transfer T1-weighted imaging: usefulness in the evaluation of brain metastases. J Magn Reson Imag 2007;25:479-87.

[21] Gore EM, Bae K, Wong SJ, et al. Phase III comparison of prophylactic cranial irradiation versus observation in patients with locally advanced non-smallcell lung cancer: primary analysis of radiation therapy oncology group study RTOG 0214. J Clin Oncol 2011;29:272-8. 